\title{
Modeling and optimization of two phase system for recycling high-speed counter-current chromatographic separation of ketoconazole enantiomers
}

\author{
Panliang Zhang ${ }^{a}$, Na Xie ${ }^{b}$, Kewen Tang $*^{a}$, Xiaoming Chen ${ }^{b}$, Weifeng Xu* ${ }^{a}$ \\ ${ }^{a}$ Department of Chemistry and Chemical Engineering, Hunan Institute of Science and \\ Technology, Yueyang, China \\ ${ }^{b}$ College of Chemistry, Xiangtan University, Xiangtan, China
}

\begin{abstract}
A B S T R A C T
An efficient method using recycling high speed counter-current chromatography (HSCCC) with hydroxypropyl- $\beta$-cyclodextrin (HP- $\beta-\mathrm{CD})$ as chiral selector $(\mathrm{CS})$ is developed for the separation of ketoconazole enantiomers. The separation process was performed with a two-phase solvent system composed of n-hexane/acetic acid isobutyl ester/ $0.1 \mathrm{~mol} \mathrm{~L}^{-1}$ phosphate buffer solution with $\mathrm{pH}=8.5$ containing $0.1 \mathrm{~mol} \mathrm{~L}{ }^{-1} \mathrm{HP}-\beta-\mathrm{CD}(2: 3: 5, \mathrm{v} / \mathrm{v} / \mathrm{v})$. Important factors that influence the separation efficiency, including organic solvent system, temperature, the $\mathrm{pH}$ value of the aqueous phase as well as type and concentration of chiral selector were investigated experimentally. Influence of the $\mathrm{pH}$ value and concentration of chiral selector was modeled and the conditions were further optimized by the model. Pure enantiomers with a purity $>99 \%$ were obtained by separating $20 \mathrm{mg}$ racemate via HSCCC. The recovery rates ranged from $85 \%$ to $89 \%$.
\end{abstract}

Keywords: Chiral separation; Hydroxypropyl- $\beta$-cyclodextrin; High speed counter-current chromatography; Ketoconazole enantiomers

\section{Introduction}

Nowadays, there is a great demand for enantiopure drugs. As it is well known that although enantiomers share the same chemical properties, they may manifest quite different biological activity and bring about unwanted side effects [1]. To obtain enantiopure compounds, some impressive separation methods such as liquid membrane [2], chromatographic techniques $[3,4]$,

\footnotetext{
* Corresponding author.

E-mail addresses: tangkewen@sina.com (K. Tang)

E-mail addresses: lotus8870@126.com
} 
crystallization techniques [5], chiral extractions [6], have been proposed. But these above methods have some limitations. The stability and lifetime of liquid membrane is not easy to control. The high cost and limited large-scale application is the main weakness in conventional chromatographic techniques. Long time consumption and low versatility is the main disadvantages of crystallization techniques. Chiral extraction is a promising method while the single-sage extraction can hardly give satisfactory separation efficiency and the multistage extraction is usually required. High-speed counter-current chromatography (HSCCC) is a liquid-liquid partitioning chromatography and unlike the conventional chromatographic techniques, it has no solid supporter which permits repetitive use of the same column for a variety of chiral separation [7-10]. As is well known, it is difficult to completely isolate enantiomers in single HSCCC operation mode when the separation factor for enantiomers is relatively low because the number of plate in HSCCC is limited. Recently, work concerning recycling mode of HSCCC has been reported $[8,10]$. Application of recycling elution mode can considerably improve the number of plate, which makes enantiomers with quite low separation factor be resolved entirely. Therefore, recycling elution mode of HSCCC has good prospect in chiral separation. Another main point in HSCCC separation of enantiomers key problem is to find a suitable chiral selector which is highly selective in the two-phase solvent system and possesses other essential properties [11-13]. So far, several chiral selectors have been successfully applied in the chiral separation by CCC [14-17], among which $\beta$-cyclodextrin derivatives [18-20] attract much attention because they are high-performance, economical and environmentally friendly. In our previous work, enantioselective extraction with a variety of $\beta$-cyclodextrins as CS was investigated [21], which is the basis of two-phase solvent system selection and optimization.

Ketoconazole, [cis-1-acetyl-4[4-[2-(2,4-dichlorophenyl)-2-(1H-imidazole-1-ylmethyl)-1,3dioxolan-4-yl]methoxyphenyl] piperazine, is an oral antifungal agent that has a broad spectrum activity (Fig. 1). Although it has two chiral centers, ketoconazole only exhibits a pairs of enantiomers, (+)-2R,4S-ketoconazole and (-)-2S,4R-ketoconazole [22,23]. This is because hydrogen atom and 2,4-dichlorophenyl in the two chiral centers must share one side as a result of space steric effect. It has been found that R-ketoconazole ((-)-2S,4R-ketoconazole) shows some times of pharmacological activity than that of S-ketoconazole ((+)-2R,4S-ketoconazole) 
[24,25]. Currently, ketoconazole is prescribed in its racemate form, which links to liver damage and other complications. Therefore, the chiral separation of ketoconazole enantiomers is not only essential but also of great significance.

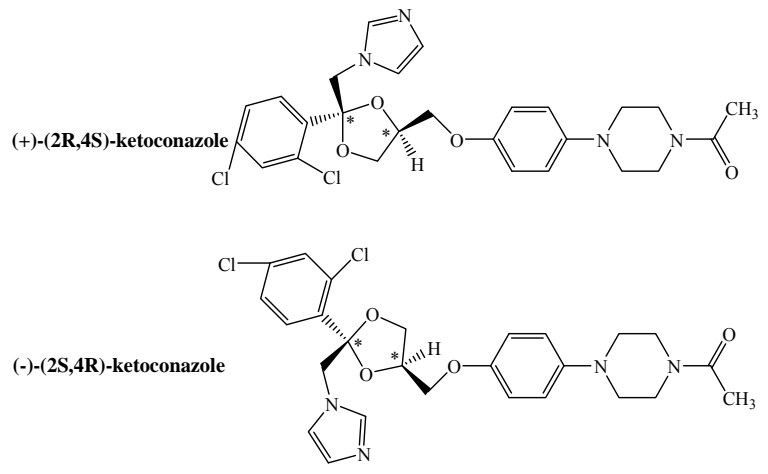

Fig. 1 Chemical structure of ketoconazole

\section{Experimental}

\subsection{Apparatus}

First of all, the TBE-300B HSCCC (Tauto Biotechnique, Shanghai, China) with three multilayer coil separation column connected in series was used. The TBE-300B preparative column consists of $1.6 \mathrm{~mm}$ ID PTFE tubing with a total capacity of $270 \mathrm{~mL}$. The $\beta$ value of the preparative columns ranged from 0.46 to $0.73,(\beta=r / R, R=6.5 \mathrm{~cm}$ for preparative columns, where $r$ is the distance from the coil to the holder shaft, and $\mathrm{R}$, the revolution radius or the distance between the holder shaft and central axis of the centrifuge). In addition, the instruments listed below were also applied, including YKKY circulating water bath, a variable wavelength UV/Vis detector, HPLC (Waters1525, USA), TBP5002 type pressure cross-flow pump, PHS-29A pH meter and TE214S electronic balance.

\subsection{Reagents}

Hydroxypropyl- $\beta$-cyclodextrin $\quad(\mathrm{HP}-\beta-\mathrm{CD}), \quad$ Sulfobutylether- $\beta$-cyclodextrin $\quad$ (SBE- $\beta$-CD), hydroxyethyl- $\beta$-clodextrin (He- $\beta-\mathrm{CD})$ and methyl- $\beta$-cyclodextrin (Me- $\beta-\mathrm{CD})$ were purchased from Shandong Binzhou Zhiyuan Bio-Technology Co., Ltd, Shandong, China. Ketoconazole racemate was obtained from Nanjing Enming Pharmaceutical Technology Co., Ltd, Nanjing, China. Solvents used such as n-hexane, dichloromethane, n-octanol, ethyl acetate, acetonitrile, were of analytical grade and from different suppliers.

\subsection{Liquid-liquid extraction experiments}


Determining the distribution ratio of ketoconazole is essential for selection of the two-phase solvent system previous to HSCCC study. Distribution ratios for ketoconazole enantiomers were calculated by the concentration of ketoconazole enantiomer in the organic phase divided by the concentration of ketoconazole enantiomer in aqueous phase. The quantitative distributions of enantiomers in the biphasic solvent system were determined by means of liquid-liquid extraction experiments under $5{ }^{\circ} \mathrm{C}$. The organic phase was prepared by dissolving racemic ketoconazole and the aqueous solution was prepared by dissolving $0.1 \mathrm{~mol} \mathrm{~L}^{-1}$ phosphate buffer solution containing (SBE-, HE-, Me-, or HP-) $\beta$-cyclodextrin. The whole extraction process was performed in a $10 \mathrm{~mL}$ plastic centrifuge tube. Equal volumes $(3 \mathrm{~mL})$ of aqueous phase (containing hydrophilic CSs) and organic phase were placed into the tube and were shaken vigorously for at least $10 \mathrm{~h}$ before being kept in a water bath at a constant temperature for $5 \mathrm{~h}$ to reach extraction equilibrium. The distributions of enantiomers were analyzed by HPLC. The solvent systems that gave the suitable distribution ratio for (+)-enantiomer and (-)-enantiomer were selected to investigate the influence factors including equilibrium temperature, concentration of HP- $\beta-C D$ and $\mathrm{pH}$ of buffer solution for the development of CCC separation.

\subsection{Preparation of two-phase solvent system and sample solution}

Solvent system consisting of n-hexane-acetic acid isobutyl ester- $0.1 \mathrm{~mol} \mathrm{~L}^{-1}$ phosphate buffer solution with $\mathrm{pH}=8.5$ containing $0.1 \mathrm{~mol} \mathrm{~L}^{-1} \mathrm{HP}-\beta-\mathrm{CD}(2: 3: 5, \mathrm{v} / \mathrm{v} / \mathrm{v})$ was used for separating ketoconazole racemate by HSCCC. Before being put into use, the solvent mixture was vigorously shaken and thoroughly equilibrated in a separatory funnel then the two phases were degassed by ultrasound for $30 \mathrm{~min}$ separately. The sample solution was prepared by dissolving $20 \mathrm{mg}$ ketoconazole racemate in $20 \mathrm{~mL}$ of organic phase (upper phase) for preparative separation.

\subsection{HSCCC separation procedure}

Conventional HSCCC: preparative separation was initiated by filling the column with the upper phase. The mobile phase was pumped into the column while the column was rotated at $850 \mathrm{rpm}$ in a "head to tail" mode in "forward" direction. The sample solution was injected after reaching hydrodynamic equilibrium, as indicated by a clear mobile phase eluting at the tail outlet. Temperature of the whole HSCCC separation procedure was set at $5{ }^{\circ} \mathrm{C}$. The absorbance of the effluent was continuously monitored at $220 \mathrm{~nm}$. 
Recycling HSCCC: Differently from the conventional HSCCC, the recycling HSCCC injected the effluent repeatedly by channeling the outlet of the detector to the inlet of the pump. The whole experimental process was carried out as follows: Firstly, the preparative separation was initiated by filling the column with the upper stationary phase of the solvent system. After the column rotated at $850 \mathrm{rpm}$, the aqueous mobile phase was pumped into it at $2.0 \mathrm{~mL} \mathrm{~min}^{-1}$. The retention rate of stationary phase of the solvent system was around 55\%. With the hydrodynamic equilibrium reaching, the sample solution containing $20 \mathrm{mg}$ ketoconazole racemate was then injected into the column. Secondly, after sample injection and shortly before the first cycle elution, the six-way valve was turned to form a recycling tube as displayed in Fig. 2. Thirdly, when the target sample was completely separated after several HSCCC cycles, the separated samples were released through turning the switching valve to its original position. Finally, the solutes were collected according to the chromatogram.

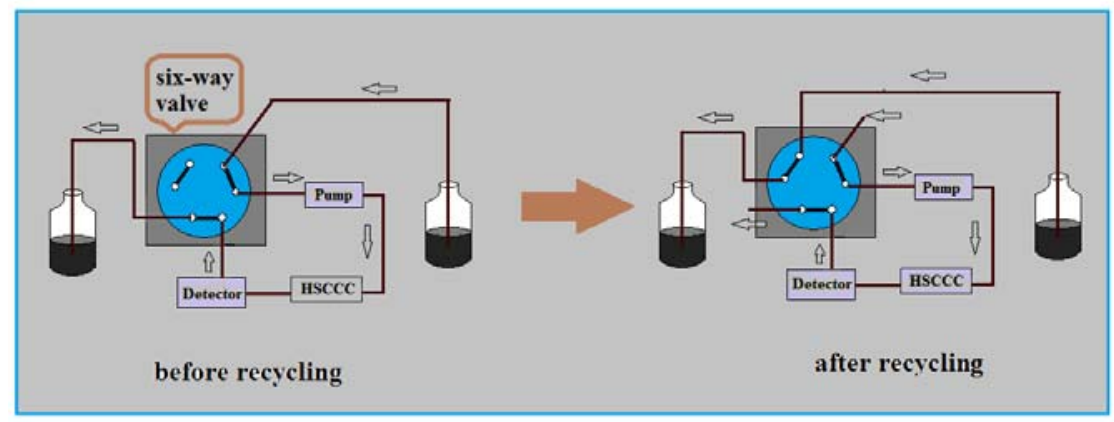

Fig. 2 Schematic diagram of six-way valve

\subsection{Recovery of solutes}

A recovery method for ketoconazole enantiomers was established when target sample was completely separated after several HSCCC cycles. The collected mobile phase fractions containing the separated enantiomers were acidified with a small volume of concentrated hydrochloric acid and extracted three times with ethyl acetate. The combined organic layers were dried with anhydrous magnesium sulfate and filtered, and then the solvent was evaporated.

\subsection{Analytical method}

The quantification of ketoconazole enantiomers was performed by HPLC using a waters 2489 $\mathrm{UV} /$ visible detector set at $240 \mathrm{~nm}$. The column was Inertsil ODS-3, with a $5 \mu \mathrm{m}$ particle size of packing material, $4.6 \mathrm{~nm} \times 250 \mathrm{~mm}$ I.D. (Dikma Technologies). The mobile phase was 
methanol-0.02 mol L-1 sodium dihydrogen phosphate buffer solution $(\mathrm{pH}=3.0$, adjusted with phosphoric acid) $(60: 40, \mathrm{v} / \mathrm{v})$, containing $1 \mathrm{mmol} \mathrm{L}^{-1} \mathrm{SBE}-\beta-\mathrm{CD}$ and $0.02 \%$ triethylamine. The flow rate was set at $0.6 \mathrm{~mL} \mathrm{~min}{ }^{-1}$ and the column temperature was set at $30^{\circ} \mathrm{C}$. The retention time of (S)-ketoconazole was less than that of (R)-ketoconazole.

\section{Results and Discussion}

\section{1 Mechanism of solute distribution}

HSCCC adopts an immiscible two-phase solvent system and removes the solid supporter of the stationary phase. The separation process of HSCCC bases on the partition of the solute between the two phases; therefore, the liquid-liquid extraction is the theoretical basis of HSCCC. In this work, the two phase solvent system for HSCCC separation of ketoconazole enantiomers was optimized by an extraction model. The mechanism of extraction is depicted in Fig. 3 and the distribution of the enantiomers is assumed in the following steps. The first step is a physical process of mass transfer of ketoconazole enantiomers, where enantiomers transfer from the organic phase to the aqueous phase. In the second step, two diastereomeric complexes between HP- $\beta-C D$ and R- and S-ketoconazole form, due to such molecular interactions as dipole-dipole, hydrophobic, Van de Waals, electrostatic, and hydrogen bonding interaction, and two acid-base dissociation equilibria exist in the aqueous phase. In the third step, the ionic solutes in the aqueous phase partition into the organic phase.

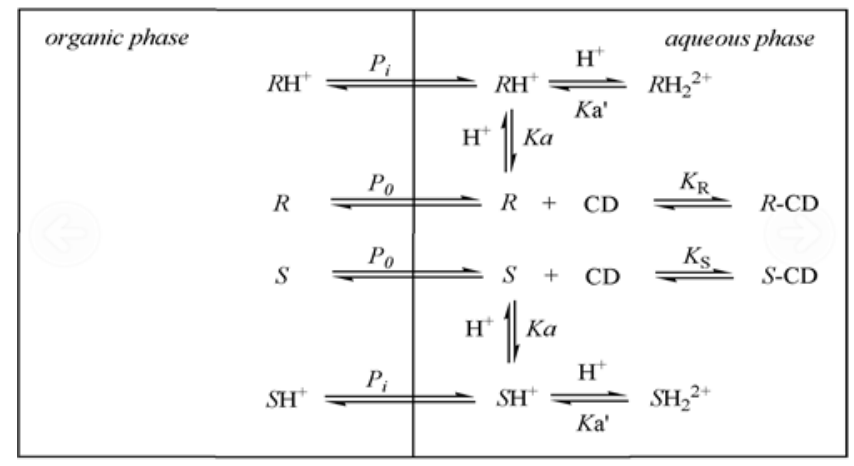

Fig. 3 Schematic diagram of equilibrium between the two phases

The liquid-liquid extraction is carried out by the formation of two inclusion complexes between ketoconazole enantiomers and HP- $\beta-C D$. The difference in free energy between the two complexes $-\triangle(\triangle G)$ is the driving forces for separation of enantiomers. 
The distribution ratios $(\mathrm{k})$ and separation factor $(\alpha)$ are the basic parameters for HSCCC separation. The distribution ratios of $\mathrm{R}$ - and $\mathrm{S}-\mathrm{ketoconazole}$ can be calculated from the following formulas, respectively

$$
\begin{aligned}
& k_{R}=C_{R, W} / C_{R, O} \\
& k_{S}=C_{S, W} / C_{S, O}
\end{aligned}
$$

Among which $C_{R, W}$ and $C_{R, O}$ represent concentrations of R-ketoconazole in aqueous phase and organic phase, respectively; $C_{S, W}$ and $C_{S, O}$ represent the concentrations of S-ketoconazole in aqueous phase and organic phase, respectively.

The separation factor is calculated through dividing the higher distribution ratio by the other one.

$$
\alpha=k_{R} / k_{S} \text {, assuming } k_{R}>k_{S}
$$

The liquid-liquid extraction equilibrium could be modeled by a series of coupled equilibrium relations and mass balance equations. In this part, the distribution ratios and separation factor of ketoconazole enantiomers were obtained by theoretical simulation. The physical partition coefficient $\left(\mathrm{P}_{0}\right)$ of molecular $\mathrm{R}$ - and S-enantiomer is depicted:

$$
P_{O}=\frac{[R]_{W}}{[R]_{O}}=\frac{[S]_{W}}{[S]_{O}}
$$

where $[R]_{O}$ and $[S]_{O}$ are the concentrations of the free R- and S-ketoconazole in the organic phase at equilibrium, respectively, and $[R]_{W}$ and $[S]_{W}$ are the concentrations of the free R- and Sketoconazole in the aqueous phase at equilibrium, respectively.

The physical partition coefficient of ionic R- and S-ketoconazole is calculated by:

$$
P_{i}=\frac{\left[R H^{+}\right]_{W}}{\left[R H^{+}\right]_{O}}=\frac{\left[S H^{+}\right]_{W}}{\left[S H^{+}\right]_{O}}
$$

Where $\left[\mathrm{RH}^{+}\right]_{\mathrm{O}}$ and $\left[\mathrm{SH}^{+}\right]_{\mathrm{O}}$ are the concentrations of the ionic R- and S-ketoconazole in the organic phase at equilibrium, respectively, and $\left[\mathrm{RH}^{+}\right]_{\mathrm{W}}$ and $\left[\mathrm{SH}^{+}\right]_{\mathrm{W}}$ are the concentrations of the ionic R- and S-ketoconazole in the aqueous phase at equilibrium, respectively.

Since ketoconazole enantiomers belong to organic acid, two dissociation equilibriums exist in 
aqueous phase according to Fig. 3. However, the first step to dissociation equilibrium is given priority to, so the second step dissociation equilibrium could be ignored in the aqueous phase. Therefore, the dissociation constant of ionic R- and S-ketoconazole could be calculated by the following equation:

$$
K_{a}=\frac{[R]_{W}\left[H^{+}\right]}{\left[R H^{+}\right]_{W}}=\frac{[S]_{W}\left[H^{+}\right]}{\left[S H^{+}\right]_{W}}
$$

The complexation equilibrium constants of HP- $\beta-C D$ with enantiomers in aqueous phase can be written as follows:

$$
\begin{gathered}
K_{R}=\frac{[R-C D]_{W}}{[R]_{W}[C D]_{W}} \\
K_{S}=\frac{[S-C D]_{W}}{[S]_{W}[C D]_{W}}
\end{gathered}
$$

Where $[R-C D]_{\mathrm{W}}$ and $[S-C D]_{\mathrm{W}}$ are the concentrations of the complexes of R-CD and S-CD in aqueous phase, respectively.

The relation of distribution ratios $(k)$ with physical distribution coefficients $\left(\mathrm{P}_{0}\right)$ and $\left(\mathrm{P}_{\mathrm{i}}\right)$, complexation equilibrium constants $\left(\mathrm{K}_{\mathrm{R}}\right)$ and $\left(\mathrm{K}_{\mathrm{S}}\right)$ and dissociation constant $\left(\mathrm{K}_{\mathrm{a}}\right)$ could be described as follows by combing the above equations:

$$
\begin{gathered}
k_{R}=\frac{P_{O} P_{i} K_{a}\left(1+\frac{\left[H^{+}\right]}{K_{a}}+K_{R}[C D]_{W}\right)}{P_{i} K_{a}+P_{O}\left[H^{+}\right]} \\
k_{S}=\frac{P_{O} P_{i} K_{a}\left(1+\frac{\left[H^{+}\right]}{K_{a}}+K_{S}[C D]_{W}\right)}{P_{i} K_{a}+P_{O}\left[H^{+}\right]}
\end{gathered}
$$

Thus, the separation factor could be deduced as:

$$
\alpha=\frac{1+\frac{\left[H^{+}\right]}{K_{a}}+K_{R}[C D]_{W}}{1+\frac{\left[H^{+}\right]}{K_{a}}+K_{S}[C D]_{W}}
$$

As shown above, the distribution ratios $(\mathrm{k})$ and separation factors $(\alpha)$ are calculated theoretically by equilibrium relations and mass balance equations.

\subsection{Selection of two-phase solvent systems}

The crucial pre work for successful enantioseparation of ketoconazole by HSCCC is to find a satisfactory CS and a suitable two-phase solvent system in which the CS retains the capacity to 
elute chiral isomers of interest. An applicable CS is the one that is highly selective. A suitable two-phase solvent system is supposed to satisfy the following requirements: first, the settling time of the solvent system should be no more than $30 \mathrm{~s}$; second, the distribution ratio of CS compound should stay in the range 0.2 to 5 ; third, the retention rate of the stationary phase need to be more than $40 \%$; forth, the CSs should be soluble in only one phase while the racemic mixtures should be easily soluble in both phases. Ketoconazole racemate shows poor solubility in the aqueous phase. Due to the complex formation between HP- $\beta-\mathrm{CD}$ and ketoconazole, ketoconazole could be soluble in the aqueous solution. $0.1 \mathrm{~mol} \mathrm{~L}^{-1} \mathrm{HP}-\beta-\mathrm{CD}$ was added into the aqueous phase in order to select an optimum solvent system. A series of solvent system were examined under $5{ }^{\circ} \mathrm{C}$ and the distribution ratios and separation factor on ketoconazole enantiomers were measured. As is shown in Table 1, distribution ratios and separation factor of the enantiomers are apparently influenced by the solvent system. Taken separation factor of enantiomers into prior consideration, the following solvent systems could be available: n-octanol: aqueous solution (1:1), acetic acid isobutyl ester: aqueous solution (1:1), n-hexane: acetic acid isobutyl ester: aqueous solution (1:5:6) and n-hexane: acetic acid isobutyl ester: aqueous solution (3:3:6). However, the distribution ratios were not in the suitable range, which lead to too short or too long retention time, except for n-hexane: acetic acid isobutyl ester: aqueous solution (2:4:6). Therefore, the solvent system of n-hexane: acetic acid isobutyl ester: aqueous solution $(2: 4: 6)$ is selected in this paper.

Table 1 The distribution ratio $(k)$ and separation factor $(\alpha)$ values of $(\mathrm{R}, \mathrm{S})$-ketoconazole in different solvent systems.

\begin{tabular}{llll}
\hline Solvent system & $\mathrm{k}_{\mathrm{R}}$ & $\mathrm{k}_{\mathrm{S}}$ & $\alpha$ \\
\hline ethyl acetate: aqueous solution (1:1) & 13.46 & 11.90 & 1.131 \\
n-Hexane : aqueous solution (1:1) & -- & -- & -- \\
n-Octanol : aqueous solution (1:1) & 15.67 & 12.98 & 1.201 \\
1,2-dichloroethane: aqueous solution (1:1) & 60.94 & 56.75 & 1.073 \\
methyl tert-butyl ether: aqueous solution (1:1) & 3.918 & 3.639 & 1.076 \\
tert-Butyl methyl ketone: aqueous solution (1:1) & -- & -- \\
acetic acid isobutyl ester: aqueous solution (1:1) & 5.830 & 4.494 & 1.297 \\
n-Hexane: acetic acid isobutyl ester: aqueous solution (1:5:6) & 2.305 & 1.895 & 1.216 \\
-Hexane: acetic acid isobutyl ester: aqueous solution (2:4:6) & 0.816 & 0.633 & 1.289 \\
$n$-Hexane: acetic acid isobutyl ester: aqueous solution (3:3:6) & 0.241 & 0.196 & 1.229 \\
$n$-Hexane: acetic acid isobutyl ester: aqueous solution (4:2:6) & 0.070 & 0.062 & 1.129
\end{tabular}

Aqueous phase: $[\mathrm{HP}-\beta-\mathrm{CD}]=0.1 \mathrm{~mol} \mathrm{~L}^{-1}, \mathrm{pH}=8.5$, and temperature $5^{\circ} \mathrm{C}$. Organic phase: $[$ ketoconazole $]=1 \mathrm{mmol} \mathrm{L}-1$. 


\subsection{Screening of CSs}

The solvent system of $n$-hexane/acetic acid isobutyl ester /aqueous solution $(2: 4: 6, \mathrm{v} / \mathrm{v} / \mathrm{v})$ was adopted with different $\beta-\mathrm{CD}$ derivatives (HP- $\beta-\mathrm{CD}$, SBE- $\beta-\mathrm{CD}$, Me- $\beta-\mathrm{CD}$ or He- $\beta-\mathrm{CD}$ ) added into the aqueous phase. In terms of the above-mentioned system, obviously, a relatively higher separation factor with good distribution ratios was obtained when HP- $\beta-C D$ is used as CS (Table 2).

Table 2 Selection of hydrophilic CSs

\begin{tabular}{llll}
\hline$\beta$-CD derivative & $\mathrm{k}_{\mathrm{R}}$ & $\mathrm{k}_{\mathrm{S}}$ & $\alpha$ \\
\hline HP- $\beta-\mathrm{CD}$ & 0.816 & 0.633 & 1.289 \\
Me- $\beta$-CD & 1.020 & 0,987 & 1.033 \\
He- $\beta$-CD & 1.011 & 1.005 & 1.005 \\
SBE- $\beta$-CD & 0.609 & 0.539 & 1.130 \\
\hline
\end{tabular}

Aqueous phase: $[\mathrm{HP}-\beta-\mathrm{CD}]=0.1 \mathrm{~mol} \mathrm{~L}{ }^{-1},[\mathrm{Me}-\beta-\mathrm{CD}]=0.1 \mathrm{~mol} \mathrm{~L}^{-1},[\mathrm{He}-\beta-\mathrm{CD}]=0.1 \mathrm{~mol} \mathrm{~L}^{-1}$, $[\mathrm{SBE}-\beta-\mathrm{CD}]=0.1 \mathrm{~mol} \mathrm{~L}^{-1}, \mathrm{pH}=8.5$, and temperature $5{ }^{\circ} \mathrm{C}$. Organic phase: $n$-hexane: acetic acid isobutyl ester (2: 4), [ketoconazole] $=1 \mathrm{mmol} \mathrm{L}^{-1}$.

3.4 Influence of some important factors in two phase system

This part mainly discusses the simulated and experimental results about the influences of the concentration of $\mathrm{CS}, \mathrm{pH}$ value of aqueous phase as well as the separation temperature on the distribution ratios and separation factor of ketoconazole enantiomers.

By varying the concentration from $0 \mathrm{~mol} \mathrm{~L}^{-1}$ to $0.25 \mathrm{~mol} \mathrm{~L}^{-1}$ at $\mathrm{pH} 8.5$, the effect of the concentration of HP- $\beta-\mathrm{CD}$ in the aqueous phase on separation factor and distribution ratios was investigated. A mathematical model was employed for modeling the influence. Detailed information about the model and determination of the required parameters was described in our previous work [21]. It is observed from Fig. 4 that the model predictions are in good agreement with experimental values. From Fig. $4 \mathrm{a}$, it can be found that with the increase of HP- $\beta-\mathrm{CD}$ concentration, the distribution ratios decrease remarkably. When the concentration of HP- $\beta-C D$ is below $0.1 \mathrm{~mol} \mathrm{~L}^{-1}$, separation factor increases remarkably, while it tends to be steady with a further increase of the concentration of HP- $\beta-C D$ (Fig. $4 b$ ). This may be because HP- $\beta-C D$ and enantiomers form a large amount of selector-enantiomer complexes in the aqueous phase, which not only greatly enhances the solubility of the enantiomers in aqueous phase, but also improves the separation factor. When HP- $\beta-C D$ is higher than $0.1 \mathrm{~mol} \mathrm{~L}^{-1}$, its selectivity tends to be saturated. 


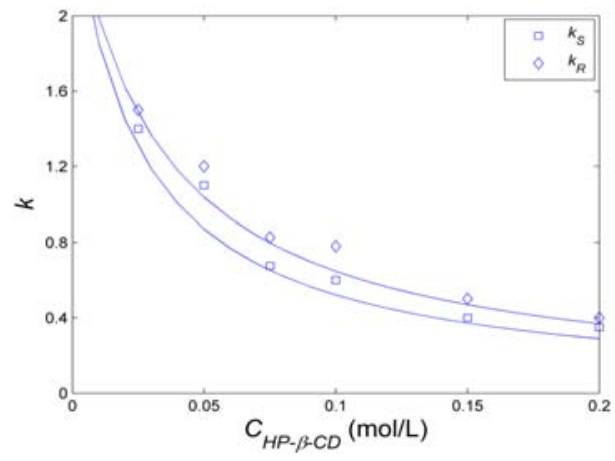

(a)

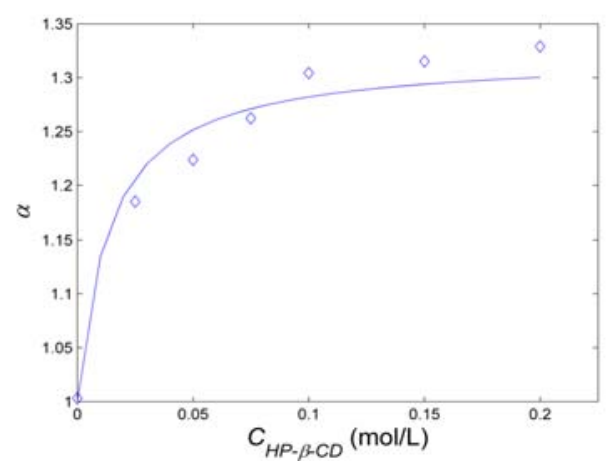

(b)

Fig. 4 Effect of the concentration of HP- $\beta$-CD on $k$ and $\alpha$ for ketoconazole enantiomers. Solid lines: model predictions. Symbols: experimental data. Organic phase: $n$-hexane: acetic acid isobutyl ester (2: 4) and aqueous phase: $\mathrm{pH}=8.5$ and temperature: $5^{\circ} \mathrm{C}$.

The $\mathrm{pH}$ value of the aqueous phase plays a significant role in the separation of ketoconazole enantiomers since it affects the state of existence of ketoconazole enantiomers in aqueous phase. Distribution ratios and separation factor were measured in a series of $\mathrm{pH}$ values of aqueous phase in order to verify the accuracy of the model predictions. The experimental values show the same trend with the model predictions of distribution ratio and separation factor as displayed in Fig. 5. With the increase of $\mathrm{pH}$ value, the distribution ratios and separation factor increase then reach the maximum. It is found that at $\mathrm{pH} 8.5$, suitable distribution ratios are obtained with satisfactory separation factor of ketoconazole enantiomers. The possible reasons for these may be that when $\mathrm{pH}$ is low, most of ketoconazole molecules are protonated and cannot be recognized by HP- $\beta-\mathrm{CD}$, which mainly has chiral recognition ability and affinity for molecular ketoconazole. With $\mathrm{pH}$ value increasing, protonated ketoconazole turns into molecular ketoconazole and is transferred from aqueous phase to organic phase. Therefore, the distribution ratios are increased. On the other 
hand, with the amount of molecular ketoconazole increasing, much more complexes between $\mathrm{HP}-\beta-\mathrm{CD}$ and ketoconazole enantiomers are formed in the aqueous phase, separation factor is therefore increased.

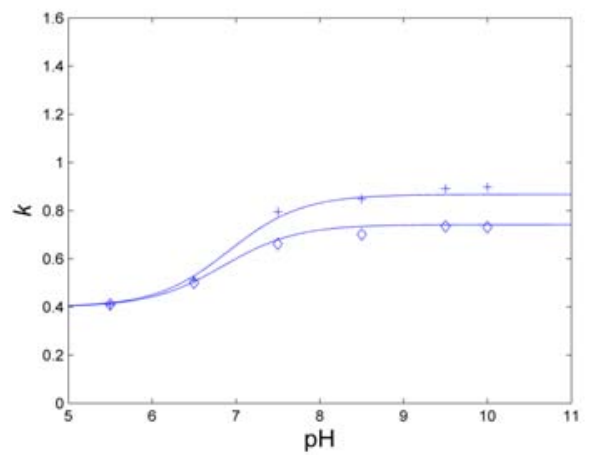

(a)

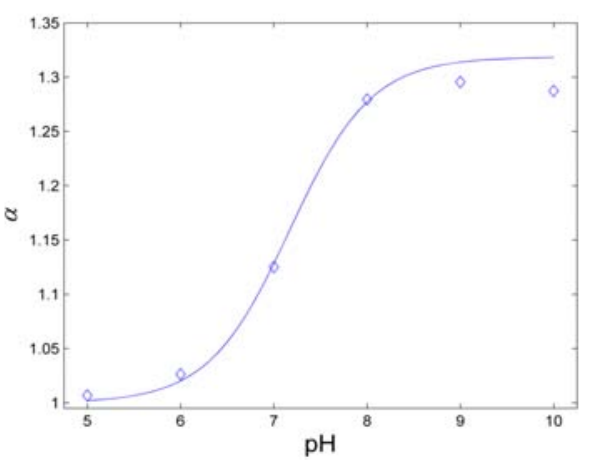

(b)

Fig. 5 Effect of $\mathrm{pH}$ on $k$ and $\alpha$ for ketoconazole enantiomers. Solid lines: model predictions. Symbols: experimental data. Organic phase: $n$-hexane: acetic acid isobutyl ester $(2: 4)$ and aqueous phase: $[\mathrm{HP}-\beta-\mathrm{CD}]=0.1 \mathrm{~mol} \mathrm{~L}^{-1}$ and temperature: $5{ }^{\circ} \mathrm{C}$. (a) “+” represents $k$ of R-ketoconazole, “ $\diamond ”$ represents $k$ of S-ketoconazole.

The influence of temperature on the distribution of ketoconazole enantiomers was measured at temperature ranging from $5{ }^{\circ} \mathrm{C}$ to $20^{\circ} \mathrm{C}$. A regular tendency is observed from Table 3 that with the temperature rising, distribution ratios increase, while separation factor decreases. The reason may be that with temperature rising, the non-selective physical partitioning between two phases is increased and the complexation between selector and enantiomers is weakened.

Table 3 Impacts of temperature on the separation of ketoconazole enantiomers

\begin{tabular}{llll}
\hline Temperature $/\left({ }^{\circ} \mathrm{C}\right)$ & $\mathrm{k}_{\mathrm{R}}$ & $\mathrm{k}_{\mathrm{S}}$ & $\alpha$ \\
\hline 5 & 0.691 & 0.536 & 1.289 \\
10 & 0.729 & 0.593 & 1.203 \\
\hline
\end{tabular}




\begin{tabular}{llll}
\hline 15 & 0.766 & 0.689 & 1.112 \\
20 & 0.845 & 0.763 & 1.108 \\
\hline
\end{tabular}

Organic phase: $n$-hexane: acetic acid isobutyl ester (2:4) and aqueous phase: $[\mathrm{HP}-\beta-\mathrm{CD}]=0.1$ $\mathrm{mol} \mathrm{L} \mathrm{L}^{-1}$ and $\mathrm{pH}=8.5$.

\subsection{Modeling and optimization of the two phase systems}

The above work shows that the model predictions are in good agreement with the experimental results, which indicates that the model provides a good means of predicting the distribution of the enantiomers in the two phase system. The influence of various operating conditions on distribution is much easier to be explored by the model.

Fig. 6 shows that the distribution ratios (Fig. 6a, Fig. 6b) and separation factor (Fig. 6c) for ketoconazole enantiomers behave as a function of HP- $\beta-\mathrm{CD}$ concentration and $\mathrm{pH}$ of the aqueous phase. The distribution ratios of R- and S- ketoconazole have the same trend as displayed in Fig. 6a and Fig. 6b, where the distribution ratios decrease with the concentration of HP- $\beta-C D$ and increase with the $\mathrm{pH}$ value of aqueous phase. This may be because ketoconazole is difficult to dissolve in water. When the concentration of HP- $\beta-C D$ is relatively low, the complexing action of ketoconazole and HP- $\beta-\mathrm{CD}$ is weak and contributes little to the solubility of ketoconazole. Most of ketoconazole enantiomers stay in the organic phase. While with the concentration of HP- $\beta$-CD getting higher, most of ketoconazole enantiomers stay in aqueous phase by forming complexes with HP- $\beta-C D$. When $\mathrm{pH}$ value increases, some of the complexes between HP- $\beta-C D$ and ketoconazole enantiomers are dissociated and some of the free enantiomers move to the organic phase, which leads to the slight increase of distribution ratios. In addition, it can be observed that high separation factor is obtained when HP- $\beta-\mathrm{CD}$ concentration and $\mathrm{pH}$ stay high at the same time. Based on the model predictions, best conditions for recycling HSCCC are obtained where aqueous $\mathrm{pH}$ value is 8.5 and concentration of $\mathrm{HP}-\beta-\mathrm{CD}$ is $0.1 \mathrm{~mol} \mathrm{~L}^{-1}$.

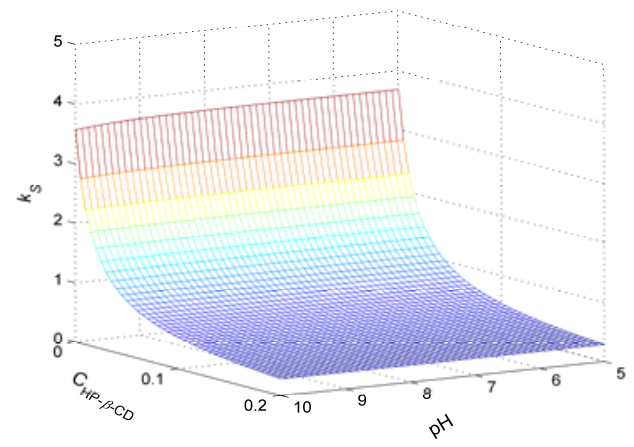


(a)

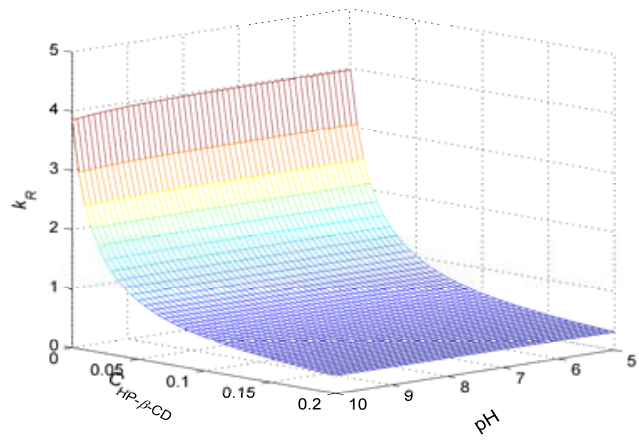

(b)

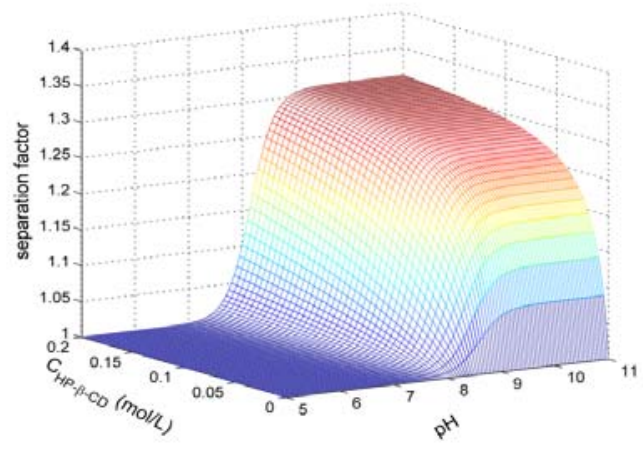

(c)

Fig. 6 Calculated distribution ratio and separation factor for ketoconazole enantiomers as a function of $\mathrm{pH}$ and HP- $\beta$-CD concentration. Organic phase: $n$-hexane: acetic acid isobutyl ester (2: 4).

\subsection{Enantioseparation of ketoconazole racemic mixtures by HSCCC}

Enantioseparation of ketoconazole was carried out by means of preparative TBE-300B instruments. Taken the relatively lower separation factor of the enantiomers into consideration, recycling high-speed counter-current chromatography was applied instead of conventional elution mode. Finally, the solvent system used was n-Hexane: acetic acid isobutyl ester: aqueous solution (2:4:6) containing $0.1 \mathrm{~mol} \mathrm{~L}^{-1} \mathrm{HP}-\beta-\mathrm{CD}$ in the aqueous phase. The retention ratio of the organic stationary phase was about $55 \%$.

As shown in Fig. 7, the cycle starts about 100 min, yielding a fork-like peak. Nevertheless, the second separation cycle exhibits a better peak, which is then divided into two in the subsequent cycles. The peak extends range from $80 \mathrm{~min}$ in the first cycle to almost $200 \mathrm{~min}$ in the fourth cycle. After the third cycle, the switching valve was returned to normal elution. Finally, the separate was 
done in the fourth cycle and the two peaks I (R-ketoconazole) and II (S-ketoconazole) were then released, collected respectively.

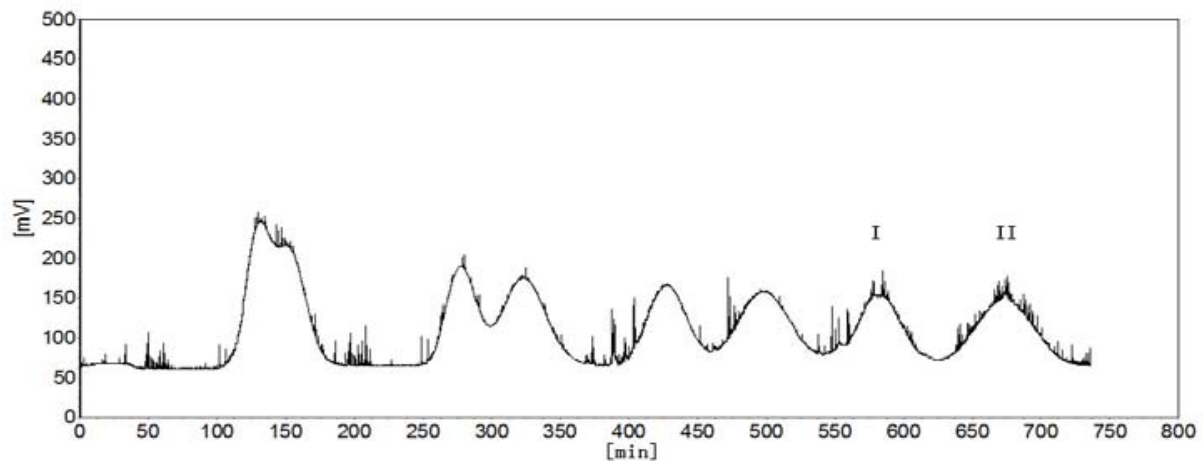

Fig. 7 Separations of ketoconazole by preparative recycling HSCCC. Experimental conditions: solvent system: $n$-hexane: acetic acid isobutyl ester: $0.1 \mathrm{~mol} \mathrm{~L}^{-1}$ phosphate salt buffer solution with $\mathrm{pH}=8.5(2: 4: 6, \mathrm{v} / \mathrm{v} / \mathrm{v})$ containing $0.1 \mathrm{~mol} \mathrm{~L}^{-1} \mathrm{HP}-\beta-\mathrm{CD}$ in the aqueous phase; sample solution: $20 \mathrm{mg}$ ketoconazole racemate was dissolved in $20 \mathrm{~mL}$ of the organic phase; flow rate: $2.0 \mathrm{~mL} \mathrm{~min}^{-1}$; revolution: $850 \mathrm{rpm}$; stationary phase retention: 55\%.

The ketoconazole racemate and the sample collected were analyzed by HPLC. As shown in Fig. 8, the retention time of R-ketoconazole and S-ketoconazole in HPLC and that in HSCCC is interchanged. This may be explained by the different mechanism of the inclusion associations between ketoconazole racemate and various cyclodextrins. The purity of the two monomers separated by HSCCC was greater than $99 \%$ and $8.9 \mathrm{mg}$ R-enantiomer and $8.5 \mathrm{mg}$ S-enantiomer were obtained after the recovery of solutes from HSCCC fraction, with a recovery rate of $85-89 \%$.

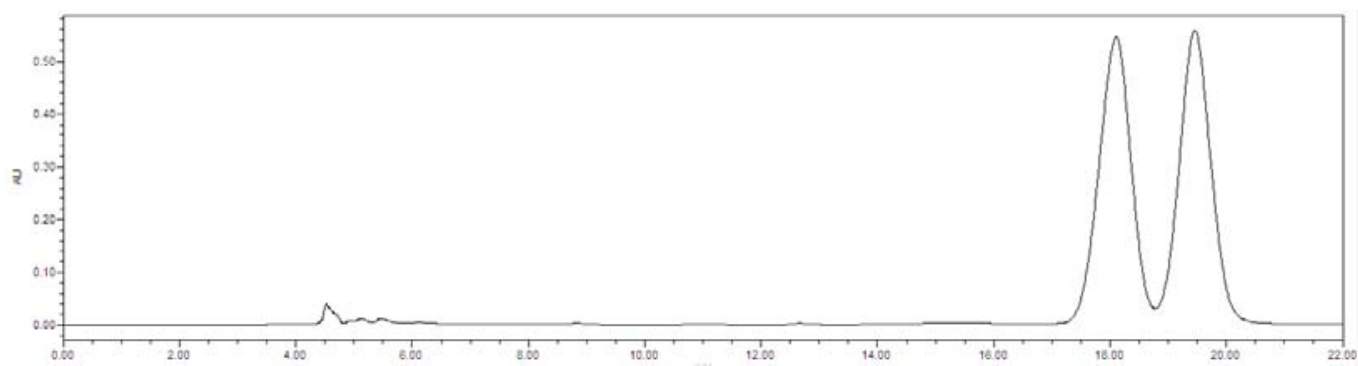

(a) 


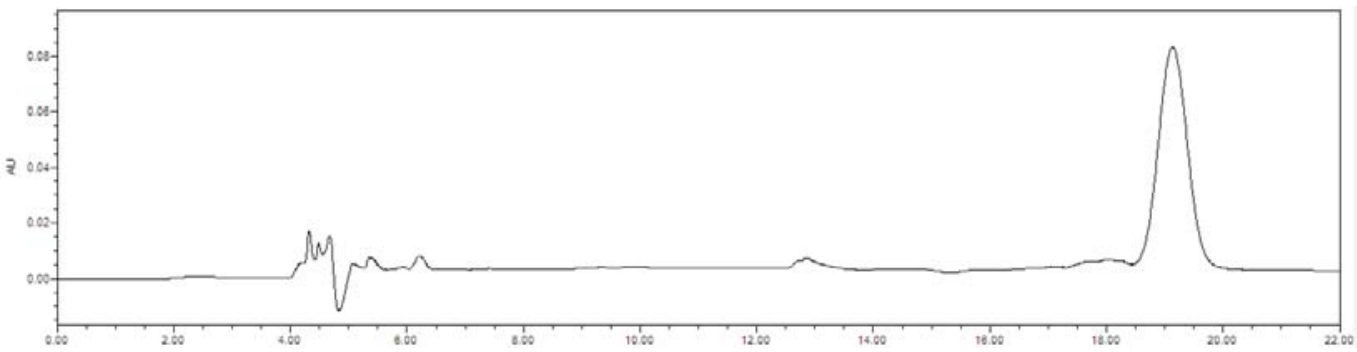

(b)

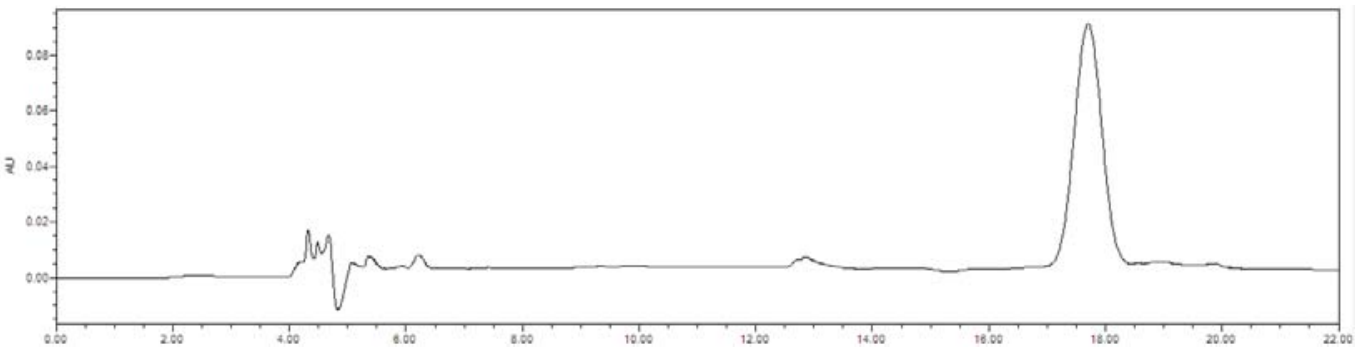

(c)

Fig. 8 Chromatogram of HPLC analyses of ketoconazole racemate and its preparative chiral HSCCC separation fractions from Fig. 7. (a) racemic mixture; (b) HSCCC fraction containing R-enantiomer; (c) HSCCC fraction containing S-enantiomer.

\section{Conclusions}

A facile method for the generation of pure optically active $R$-ketoconazole and $S$-ketoconazole via resolution of ketoconazole enantiomers using the preparative recycling HSCCC system is investigated. To the best of our knowledge, it is the first time for the chiral separation of ketoconazole racemate through preparative recycling HSCCC system. The method avoids the use of a solid supporter, and the separation process can be performed under ambient conditions, rendering the experimental procedure simple. Modeling the distribution of the enantiomers between the two phase provide a useful tool for optimizing the solvent system. Therefore, this separation method has high potential in the preparative resolution of drug enantiomers.

\section{Abbreviation}

HSCCC high-speed counter-current chromatography

CS chiral selector

HP- $\beta$-CD hydroxypropyl- $\beta$-cyclodextrin

He- $\beta$-CD hydroxyethyl- $\beta$-cyclodextrin

Me- $\beta$-CD methyl- $\beta$-cyclodextrin 
SBE- $\beta$-CD sulfobutyl ether- $\beta$-cyclodextrin

\section{Acknowledgements}

This work was supported by the National Science Foundation of China (No. 21376071), the planned Science and Technology project of Hunan Province, China (No. 2013SK3166), and Aid program for Science and Technology Innovative Research Team in Higher Educational Institutions of Hunan Province.

\section{References}

[1] A.J. Hutt, Drug chirality: impact on pharmaceutical regulation, Chirality 3 (1991) 161-164.

[2] C.A.M. Afonso, J.G. Crespo, Recent advances in chiral resolution through membrane-based approaches, Angew. Chem. Int. Ed. 43 (2004) 5293-5295.

[3] T.J. Ward, B.A. Baker, Chiral separations, Anal. Chem. 80 (2008) 4363-4372.

[4] Q. Liu, J.N. Xiao, J.G. Yu, Y.X. Xie, X.Q. Chen, H. Yang, Improved enantioseparation via the twin-column based recycling high performance liquid chromatography, J. Chromatogr. A 1363 (2014) 236-241.

[5] M.D. Gourlay, J. Kendrick, F.J.J. Leusen, Predicting the spontaneous chiral resolution by crystallization of a pair of flexible nitroxide radicals, Cryst. Growth. Des. 8 (2008) 2899-2905.

[6] K.W. Tang, J.M. Yi, Y.B. Liu, X.Y. Jiang, P. Yang, Enantioselective separation of R, S-phenylsuccinic acid by biphasic recognition chiral extraction, Chem. Eng. Sci. 64 (2009) 4081-4088.

[7] S. Liu, B. Wang, B. Li, X.Z. L.F. Qi, Y.Z. Liang, Preparative separation and purification of liensinine, isoliensinine and neferine from seed embryo of Nelumbo nucifera GAERTN using high - speed counter - current chromatography, J. Sep. Sci. 32 (2009) 2476-2481.

[8] J. Xie, J. Deng, F. Tan, J. Su, Separation and purification of echinacoside from Penstemon barbatus (Can.) Roth by recycling high-speed counter-current chromatography, J. Chromatogr. B 878 (2010) 2665-2668.

[9] F. Qiu, J.G. Luo, X. Yao, L. Ma, L.Y. Kong, Efficient isolation and purification of five products from microbial biotransformation of cinobufagin by high speed counter - current chromatography, J. Sep. Sci. 32 (2009) 2146-2151.

[10] S.Q. Tong, Y.X. Guan, J.Z. Yan, B. Zheng, L.Y. Zhao, Enantiomeric separation of (R, 
S)-naproxen by recycling high speed counter-current chromatography with hydroxypropyl - $\beta$ - cyclodextrin as chiral selector, J. Chromatogr. A 1218 (2011) 5434-5440.

[11] B. Delgado, E. Pérez, M.C. Santano, C. Minguillón, Enantiomer separation by counter current chromatography: Optimisation and drawbacks in the use of L-proline derivatives as chiral selectors, J. Chromatogr. A 1092 ( 2005) 36-42.

[12] G.L. Sun, K.W. Tang, P.L. Zhang, W.J. Yang, G.Q. Sui, Separation of phenylsuccinic acid enantiomers using biphasic chiral recognition high speed counter - current chromatography, J. Sep. Sci. 37 (2014) 1736-1741.

[13] S.Q. Tong, J.Z. Yan, Y.X. Guan, Y.E. Fu, Y. Ito, Separation of $\alpha$-cyclohexylmandelic acid enantiomers using biphasic chiral recognition high-speed counter-current chromatography, J. Chromatogr. A 1217 (2010) 3044-3052.

[14] Y.C. Lv, Z.H. Yan, C. Ma, L.M. Yuan, Preparative enantioseparation of ofloxacin by high speed countercurrent chromatography using L-(+)-tartaric acid as chiral selector, J. Liq. Chromatogr. Rel. Technol. 33 (2010) 1328-1334.

[15] N. Rubio, S. Ignatova, C. Minguillón, I.A. Sutherland, Multiple dual-mode countercurrent chromatography applied to chiral separations using a (S)-naproxen derivative as chiral selector, J. Chromatogr. A 1216 (2009) 8505-8511.

[16] P.L. Zhang, G.L. Sun, K.W. Tang, Separation of amlodipine besilate enantiomers by biphasic recognition recycling high-speed counter-current chromatography, Sep. Purif. Technol. 146 (2015) 276-283.

[17] A.M. Pérez, C. Minguillón, Retention of fluorinated chiral selectors in biphasic fluorinated solvent systems and its application to the separation of enantiomers by countercurrent chromatography, J. Chromatogr. A 1217 (2010) 1094-1100.

[18] Y. Wei, S. Du, Y. Ito, Enantioseparation of lomefloxacin hydrochloride by high-speed counter-current chromatography using sulfated- $\beta$-cyclodextrin as a chiral selector, J. Chromatogr. B 878 (2010) 2937-2941.

[19] L.M. Yuan, C. Liu, Z.H. Yan, P. Ai, X. Meng, Z.G Xu, Enantioseparation of chlorpheniramine by high speed countercurrent chromatography using carboxymethyl- $\beta$-cyclodextrin as chiral selector, J. Liq. Chromatogr. Rel. Technol. 28 (2005) 3057-3063. 
[20] P. Ai, C. Liu, M. Zi, Z. Deng, Z.H. Yan, L.M. Yuan, Enantioseparation of aminoglutethimide by high-speed counter-current chromatography using carboxymethly- $\beta$-cyclodextrin as chiral select, Chin. Chem. Lett. 17 (2006) 787-794.

[21] K.W. Tang, P.L. Zhang, C.Y. Pan, H.J. Li, Equilibrium studies on enantioselective extraction of oxybutynin enantiomers by hydrophilic $\beta$-cyclodextrin derivatives, AIChE J. 11 (2011) 3027-3036.

[22] D.M. Rotstein, D.J. Kertesz, K.A.M Walker, D.C. Swinney, Stereoisomers of ketoconazole: preparation and biological activity, J. Med. Chem. 35 (1992) 2818-2825.

[23] M. Castro-Puyana, A.L. Crego, M.L. Marina, Enantiomeric separation of ketoconazole and terconazole antifungals by electrokinetic chromatography: rapid quantitative analysis of ketoconazole in pharmaceutical formulations, Electrophoresis 26 (2005) 3960-3968.

[24] S. Dilmaghanian, J.G. Gerber, S.G. Filler, A. Sanchez, J. Gal, Enantioselectivity of inhibition of cytochrome P4503A4 (CYP3A4) by ketoconazole: testosterone andmethadone as substrates, Chirality 16 (2004) 79-85.

[25] P. Camps, J. Ginesta, D. Mauleón, G. Carganico, Stereoselective synthesis of both enantiomers of ketoconazole from (R)- and (S)-epichlorohydrin, Tetrahedron: Asymmetry 6 (1995) 1283-1294. 